\title{
3,4-diaminopyridine in the treatment of congenital (hereditary) myasthenia
}

\author{
J Palace, C M Wiles, J Newsom-Davis
}

\begin{abstract}
Congenital or hereditary myasthenia describes a heterogeneous group of disorders in which the immune system is not implicated. Treatment has previously depended on anticholinesterase medication. The effectiveness of 3,4-diaminopyridine (3,4-DAP), a preparation that enhances acetylcholine release from motor nerve terminals, has been evaluated using a series of standardised strength measures. Sixteen patients (aged seven to 47 years) were studied in an open prospective trial, and four of them in a double blind crossover trial; existing anticholinesterase medication was continued. For the group as a whole, there was a highly significant increase in muscle strength $(p<0.001 ; n=16)$. In individual paired comparisons, 13 out of 16 showed significant improvement in the open trial and four out of four in the blind crossover trial. In conclusion, 3,4-DAP, either alone or combined with anticholinesterase medication, may be a useful additional treatment in congenital myasthenia.
\end{abstract}

Congenital or hereditary myasthenia (CM) refers to a heterogenous group of disorders with impaired neuromuscular transmission, usually presenting at birth or in early childhood. ${ }^{1}$ There is often a relevant family history. Patients may show fatiguable or persistent weakness of the ocular, bulbar, facial, trunk or limb muscles. Weakness is not usually progressive and in some cases strength improves during adolescence. In contrast to the acquired disease myasthenia gravis, which is associated with antibodies to the acetylcholine receptor (AChR), CM has a non-immunological pathology. Several different types of abnormality at the end plate have been reported. These include a deficiency in acetylcholine release (familial infantile myasthenia), ${ }^{2}$ a postsynaptic defect in which the number of AChRs is reduced, ${ }^{3}$ and the slow channel syndrome, ${ }^{45}$ in which the open time of the AChR channel is prolonged. Inheritance appears to be autosomal recessive in the first two, and dominant in the latter.

Treatment of $\mathrm{CM}$ is usually unsatisfactory. Some forms respond to anticholinesterase medication, but full return of strength is unusual and many patients continue to have disabling weakness. The compound 3,4 diaminopyridine $(3,4-\mathrm{DAP})$ is a potential therapeutic agent for disorders of neuromuscular transmission. It acts by blocking $\mathrm{K}^{+}$ conductance and increasing nerve terminal acetylcholine release. ${ }^{6-8}$ It has been shown to be effective in the treatment of patients with the pre-synaptic Lambert-Eaton myasthenic syndrome. ${ }^{9}$ The related preparation 4-aminopyridine was shown to be effective in two out of four patients with CM, but CNS side effects were a major drawback. ${ }^{10} 3,4-\mathrm{DAP}$, by contrast, has only limited access to the CNS. Its benefits in a single case of CM have been reported briefly. ${ }^{11}$ We have evaluated, in a prospective trial, the effectiveness of 3,4-DAP in combination with anticholinesterase medication in a group of 16 patients with CM.

\section{Methods}

\section{Patients}

Eighteen patients were available for study who met the following criteria: 1) Fatiguable weakness of striated muscle; 2) Electromyographic (EMG) evidence of abnormal neuromuscular transmission (decrement $>10 \%$ after five stimuli at $3 \mathrm{~Hz}$ and/or jitter $>53 \mu$ s on a single fibre EMG); 3) Absence of antiacetylcholine receptor antibodies, measured by radioimmunoassay using human acetylcholine receptor as antigen. ${ }^{12}$

Most patients had onset in early life and showed a relatively stable clinical state in contrast to myasthenia gravis. Most of them also responded to antiacetylcholinesterase medication, but two did not. Parental consanguinity or an affected sibling was present in eight cases. Two patients were excluded because strength measures showed that they were functioning within $5 \%$ of the normal range (see below). Sixteen patients therefore entered the study (table 1 ).

\section{Protocol}

3,4-DAP (Small Scale Pharmaceuticals) was made up with standard pharmaceutical exipient materials. All patients were assessed in an open prospective study before and during 3,4-DAP medication. Between 5-20 mg of 3,4DAP was given orally three or four times daily, the dose and frequency being adjusted to be optimal for each patient. All but four patients were already receiving pyridostigmine on entry to the trial, and continued to do so (table 2).

Four patients (age $>16$ years) were additionally entered into a randomised blind crossover trial taking either 3,4-DAP or an inactive preparation of identical appearance for a month, before switching to the alternative 
Table 1 Clinical details

\begin{tabular}{|c|c|c|c|c|c|c|}
\hline \multirow{2}{*}{$\begin{array}{l}\text { Case } \\
\text { number }\end{array}$} & \multirow[b]{2}{*}{ Sex } & \multirow[b]{2}{*}{ Family history } & \multicolumn{2}{|l|}{$A g e^{\star}$} & \multirow{2}{*}{$\begin{array}{l}\text { Edrophonium } \\
\text { test }\end{array}$} & \multirow{2}{*}{$\begin{array}{l}\text { Electro- } \\
\text { myography } \dagger\end{array}$} \\
\hline & & & at onset & at study & & \\
\hline 1 & Male & Sibling affected & $1.5 \mathrm{y}$ & $21 \mathrm{y}$ & + & $\mathbf{J}$ \\
\hline 2 & Female & Sibling case 14 & $<1 \mathrm{y}$ & $32 \mathrm{y}$ & + & D \\
\hline 3 & Male & & birth & $15 \mathrm{y}$ & + & D \\
\hline 4 & Male & Sibling affected & birth & $21 \mathrm{y}$ & - & D \\
\hline 5 & Female & Parental consanguinity & $8 y$ & $17 \mathrm{y}$ & + & $\mathbf{J}$ \\
\hline 6 & Female & - & neonate & $16 \mathrm{y}$ & + & D \\
\hline 7 & Male & - & $<1 \mathrm{y}$ & $14 \mathrm{y}$ & + & $\mathrm{J}$ \\
\hline 8 & Female & - & birth & $47 y$ & & $\mathrm{~J}$ \\
\hline 9 & Female & & $1 \mathrm{~m}$ & $45 y$ & & D \\
\hline 10 & Male & Sibling case 11 & birth & $11 \mathrm{y}$ & + & $\bar{D}$ \\
\hline 11 & Female & Sibling case 10 & $4 \mathrm{~m}$ & $7 \mathrm{y}$ & + & $\mathbf{D}$ \\
\hline 12 & Female & & $9 \mathrm{~m}$ & $32 \mathrm{y}$ & - & $\bar{J}$ \\
\hline 13 & Male & Parental consanguinity & birth & $32 \mathrm{y}$ & + & $\mathrm{J}$ \\
\hline 14 & Female & Sibling case 2 & $1.2 \mathrm{y}$ & $38 \mathrm{y}$ & + & $\mathrm{J}$ \\
\hline 15 & Male & - & birth & $8 y$ & + & D \\
\hline 16 & Male & - & $14 \mathrm{y}$ & $30 y$ & - & D \\
\hline
\end{tabular}

Table 2 Drug dosages

\begin{tabular}{|c|c|c|c|c|}
\hline \multirow[b]{2}{*}{ Case number } & \multicolumn{2}{|c|}{ Pyridostigmine } & \multicolumn{2}{|c|}{ 3,4-diaminopyridine } \\
\hline & dose (mg) & frequency per day & dose (mg) & frequency per day \\
\hline 1 & 60 & 5 & 10 & 4 \\
\hline 2 & 60 & 4 & 10 & 4 \\
\hline 3 & 60 & 4 & 20 & 4 \\
\hline 4 & 60 & 4 & 20 & 4 \\
\hline 5 & 60 & 5 & 20 & 4 \\
\hline 6 & 30 & 4 & 20 & 4 \\
\hline 7 & - & - & 10 & 4 \\
\hline 8 & 60 & 3 & 10 & 3 \\
\hline 9 & - & - & 10 & 3 \\
\hline 10 & 30 & 4 & 10 & 4 \\
\hline 11 & 30 & 4 & 10 & 4 \\
\hline 12 & - & - & 20 & 4 \\
\hline 13 & 30 & 4 & 20 & 4 \\
\hline 14 & 60 & 6 & 10 & 4 \\
\hline 15 & 30 & 4 & 5 & 4 \\
\hline 16 & - & - & 20 & 4 \\
\hline
\end{tabular}

preparation for a further month. Assessments were performed before entry, and at the end of each month of treatment. Informed consent was obtained, and the trial was approved by the hospital Ethics Committee.

\section{Assessment of muscle strength}

1) Myometry was carried out using either a hand held dynamometer or for knee extension, a muscle testing chair (as previously described $^{13}$ ). At least eight of the following muscles or muscle groups were tested: neck flexors, elbow extensors, elbow flexors, first dorsal interosseous, abductor digiti minimi, shoulder abductors, hip flexors, hip abductors, knee extensors. Positioning normally eliminated the effects of gravity in all muscle groups except for some measures of hip and shoulder abduction.

2) Vital capacity, measured when seated.

3) Timed walk of $30 \mathrm{~m}$, turning half way.

4) Timed drink of $150 \mathrm{ml}$ of water.

\section{Analysis of data}

Values for the strength measures 1,3 and 4 above in a control population $(n=60)$, have been determined by Wiles et $a l,{ }^{13}$ and were corrected for sex, but not for age. Control values for the vital capacity were obtained from standard values based on height and weight.

Each individual measurement in our study was expressed as a percentage of the lower limit of normal (\%LLN), that is, the value two standard deviations below the mean for controls. The mean value of these measures ("mean strength") was then calculated for each patient, excluding individual measures that were within $5 \%$ of the normal range, that is, only muscle groups that were clearly weak were included for analysis. Because the data of Wiles et $a l^{13}$ were not corrected for age, the mean strength values for the children (cases 10, 11 and 15) of necessity appear unduly low.

\section{Statistics}

The mean strength for each patient pre- and post-3,4-DAP therapy were analysed for the group as a whole and also individually using the non-parametric Wilcoxon paired samples test and the Student's paired $t$ test.

\section{Results}

Initial Response

Fourteen patients were assessed within the first seven days of starting 3,4-DAP after the optimal dose had been established. The mean muscle strength in each case is shown before and during treatment in fig 1 . All except case 16 showed an improvement in their strength scores. Patients have been ranked in this figure in order of their pre-treatment scores. The Wilcoxon signed rank test (two tailed) was applied to these data, and showed a statistically significant improvement in mean strength scores when $3,4-D A P$ was added $(p=0.0002$; $\mathrm{n}=14$ ).

\section{Long term response}

This was studied in four patients (cases 4, 8, 13, 1). Improvement was observed in the first three of these (table 3) assessed before and after at least a month of treatment. In two (cases 4 and 13), the initial response had also been measured (fig 1). Case 4 was admitted to hospital for reassessment after five years of treatment. 3,4DAP was withdrawn for 48 hours. Strength measurements were then made and repeated one hour after a single $20 \mathrm{mg}$ dose of 3,4-DAP. Fig 2 shows the improvement in strength after starting 3,4-DAP, and a further improvement when treatment was established, and very 


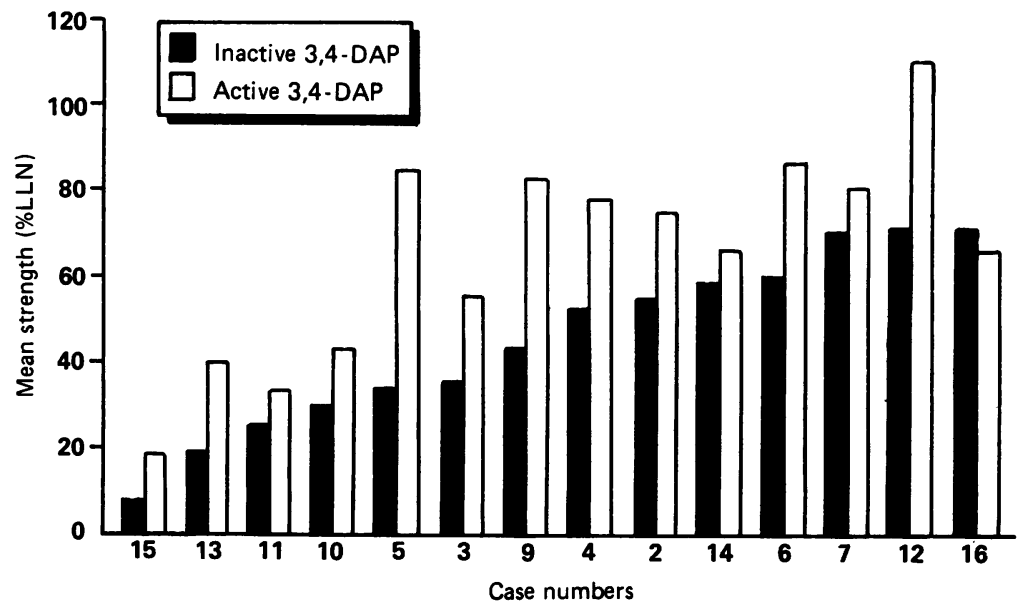

Figure 1 The initial response (open trial) of 14 patients to 3,4-DAP therapy. Individual patients (identified by their case number) are shown on the horizontal axis, and their mean strength score on the vertical axis. All except one patient (case 16) showed an improvement in their mean strength scores. Cases 10 and 11 , and 2 and 14 are sibling pairs. similar results five years later when measured by a different assessor.

\section{Comparison of strength measures}

To compare the effects of 3,4-DAP treatment between individual patients, the data in all 16 patients (14 initial response, two long term response) have been normalised by expressing them as the percentage change in mean strength (fig 3). Fourteen patients showed improvement in strength ranging from $12 \%$ to $142 \%$. In the two patients showing no improvement, the values for $\%$ change were $-6 \%$ and $-7 \%$ respectively. For the group as a whole, there was a highly significant increase in muscle strength $(\mathrm{p}<0.001, \mathrm{n}=16$; Student's paired $t$ test).

\section{Individual patient analysis}

Analysis of the different measures $(n=8-10)$ made in each of the 16 patients before and during treatment with 3,4-DAP, showed a significant improvement in 13 (table 3; 1-tailed $t$ test). One patient (case 16) was significantly worse.

Table 3 Individual strength measures

\begin{tabular}{|c|c|c|c|c|c|}
\hline \multirow[b]{2}{*}{ Case number } & \multicolumn{2}{|c|}{ Mean strength ${ }^{\star}(\%)$ 3,4-DAP } & \multirow[b]{2}{*}{$n_{1} \dagger$} & \multirow[b]{2}{*}{$n_{2} \ddagger$} & \multirow[b]{2}{*}{ p value (1-tailed) } \\
\hline & pre- & post- & & & \\
\hline $\begin{array}{r}1 \\
2 \\
3 \\
4 \\
5 \\
6 \\
7 \\
8 \\
9 \\
9 \\
10 \\
11 \\
12 \\
13 \\
14 \\
15 \\
16\end{array}$ & $\begin{array}{r}66 \\
41 \\
36 \\
53 \\
35 \\
60 \\
70 \\
63 \\
44 \\
30 \\
26 \\
71 \\
23 \\
59 \\
8 \\
71\end{array}$ & $\begin{array}{r}62 \\
55 \\
55 \\
78 \\
85 \\
86 \\
80 \\
94 \\
83 \\
43 \\
34 \\
110 \\
48 \\
66 \\
19 \\
66\end{array}$ & $\begin{array}{r}10 \\
9 \\
9 \\
9 \\
9 \\
9 \\
9 \\
9 \\
9 \\
8 \\
8 \\
9 \\
9 \\
9 \\
9 \\
9\end{array}$ & $\begin{array}{l}8 \\
6 \\
7 \\
8 \\
8 \\
5 \\
5 \\
5 \\
5 \\
7 \\
8 \\
7 \\
6 \\
7 \\
7 \\
9 \\
6\end{array}$ & $\begin{array}{r}-0.116 \\
0.004 \\
0.002 \\
0.002 \\
0.002 \\
0.006 \\
0.002 \\
0.049 \\
0.014 \\
0.004 \\
0.004 \\
0.006 \\
0.002 \\
0.014 \\
0.004 \\
-0.037\end{array}$ \\
\hline
\end{tabular}

¿Expressed as \% of LLN of healthy controls.

$\dagger$ Total number of measures for each patient.

†Number of measures after exclusion of values within $5 \%$ of the normal range (see Methods: analysis of data).

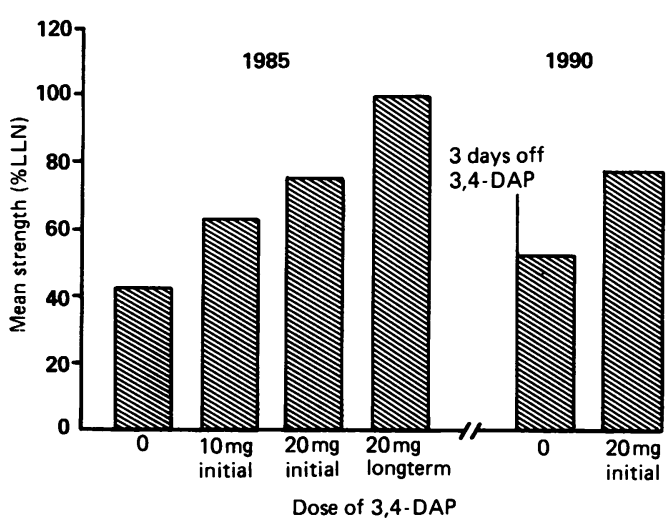

Figure 2 The response to 3,4-DAP treatment in case 4 over a five year period. The horizontal axis represents time and the dose of 3,4-DAP taken is shown against the patient's mean strength score on the vertical axis. The drug was first started in 1985, then stopped for three days and re-started in 1990.

\section{Randomised blind crossover trial}

Four patients over the age of 16 years agreed to enter a blind crossover trial, and were randomly assigned to one month on either the active or inactive 3,4-DAP preparation, and then switching to the alternative preparation for a second month. The clinical assessor was not told which preparation the patient was receiving. The patients themselves could often guess from the perioral and distal limb

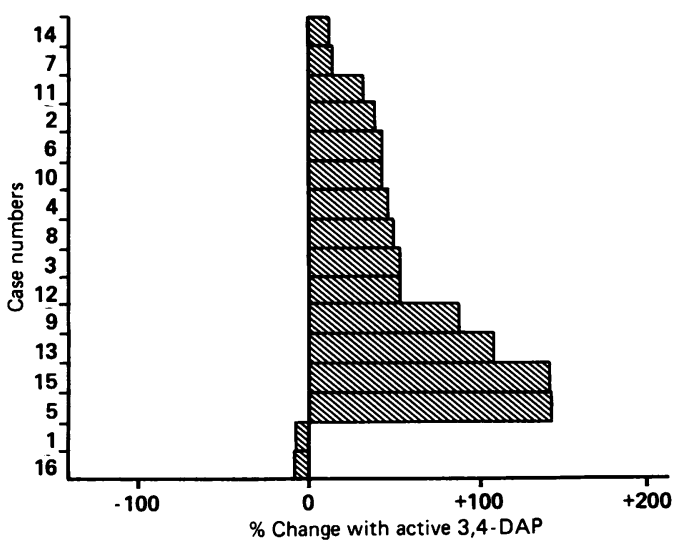

Figure 3 The percentage change in mean strength with 3,4-DAP therapy in 16 patients. Two of these (cases 1 and 8) are long term responses. The individual cases are represented on the vertical axis and their percentage change in mean strength (positive score for improvement, negative score for reduction) is shown on the horizontal axis.

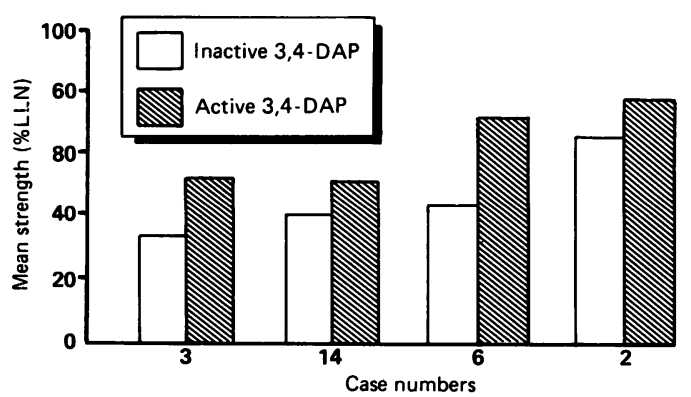

Figure 4 Blind crossover trial in four patients treated with either active or inactive 3,4-DAP. The respective mean strength scores are shown on the vertical axis. All four patients were stronger taking the active 3,4-DAP preparation. 
parasthesia they experienced whether the preparation was active or not. Each of the four patients improved significantly on the 3,4-DAP (fig 4), p values ranging from 0.01 to 0.002 (Wilcoxon).

\section{Discussion}

The compound 3,4-DAP when taken orally either alone or in conjuction with continued pyridostigmine therapy resulted in a statistically significant overall improvement ( $p$ $<0.001$ ) in muscle strength in a group of 16 patients with congenital myasthenia. Early improvement appeared to be sustained in those tested after periods of treatment ranging from one month to five years.

Multiple performance measures including muscle force for selected muscle groups have been shown to provide a reliable index of muscle strength. ${ }^{13}$ They are non-invasive, welltolerated by patients, and not unduly timeconsuming. Further evidence of their reliability is provided in this study, in which measures made on widely separate occasions showed considerable similarity. To avoid masking the potential benefits of the medication in the group analysis, we excluded strength measures that were either within the range of a group of healthy adult controls, or less than $5 \%$ below this. This might have resulted in the inclusion of some measures in the children that were in fact within the normal range for age. Each of the children tested individually, however, showed a highly significant improvement with 3,4-DAP (table 2).

In most of the cases studied, the type of CM had not been established. However, in one of them (case 4) intercostal muscle biopsy indicated that the disorder was likely to be presynaptic, ${ }^{3}$ and the result in this individual was among the most statistically significant. By contrast, case 16, who failed to respond to edrophonium and whose end plate biopsy showed changes suggestive of the slow channel syndrome (W Squier, personal communication), strength measures were significantly decreased while he was receiving 3,4-DAP, as might be expected. These patients are also known not to respond to anticholinesterase preparations. $^{5}$

Side effects have not proved to be troublesome at the dose prescribed. This was also the case in the reported usage of 3,4-DAP in the Lambert-Eaton myasthenic syndrome. ${ }^{9}$
Most of our patients experienced perioral or distal parasthesia and some were aware of, or exhibited, mild hyperexcitability during the initial period of dose adjustment. The youngest patient in our study who received 3,4-DAP was seven years old and tolerated the drug well. A five year old girl with severe CM, who was not included in this study, also showed a striking improvement in muscle strength while taking the drug. After receiving it at home without incident for several weeks, she developed a fatal pneumonia. However, it was not thought that 3,4-DAP had contributed to this.

The results of our study suggest that 3,4DAP, either combined with existing anticholinesterase medication or alone, may be a useful additional treatment in many cases of CM.

We thank Dr NMF Murray and Dr $\mathrm{K}$ Mills for the initial electrophysiological studies and Miss Y Karni and Miss J Nicklin for carrying out some of the strength measurements. This research was supported by the Myasthenia Gravis AssociaThis research was supported by the Myasthen
tion and the Muscular Dystrophy Group.

1 Newsom-Davis J. Diseases of the neuromuscular junction. In: AK Asbury, GM McKhann, WI McDonald, eds. Diseases of the nervous system. Philadelphia; Saunders, 1986:269-82.

2 Mora M, Lambert EH, Engel AG. Synaptic vesicle abnormality in familial infantile myasthenia. Neurology 1987;37:206-14.

3 Vincent A, Cull-Candy SG, Newsom-Davis J, Trautman A Molenaar PC, Polak RL. Congenital myasthenia, endplate acetylcholine receptors and electrophysiology in five cases. Muscle Nerve 1981;4:306-18.

4 Engel AG, Lambert EH, Mulder DM, et al. A newly recognised congenital myasthenic syndrome attributed to a prolonged open time of the acetylcholine-induced ion channel. Ann Neurol 1982;11:553-69.

5 Oosterhuis HJGH, Newsom-Davis J, Wokke JHJ, et al. The slow channel syndrome: two new cases. Brain 1987;110. 1061-79.

6 Harvey AL, Marshall IG. The actions of three diaminopyridines on the chick biventer cervicis muscle. Eur Pharmacol 1977;44:303-9.

7 Kirsch GE, Narahashi T. 3,4-Diaminopyridine: a potent new potassium channel blocker. Biophys $J$ 1978;22: 507-12.

8 Molgó J, Lundh H, Thesleff S. Potency of 3,4-diaminopyridine and 4-aminopyridine on mammalian neuropyridine and 4-aminopyridine on mammalian neuroPharcular transmission and

9 McEvoy KM, Windebank AJ, Daube JR, Low PA. 3,4Diaminopyridine in the treatment of Lambert-Eaton myasthenic syndrome. N Engl J Med 1989;321:1567-71.

10 Murray NMF, Newsom-Davis J. Treatment with oral 4 aminopyridine in disorders of neuromuscular transmission. Neurology 1981;31:265-71.

11 Sanders DB, Massey JM, Howard JF. 3,4-Diaminopyridine in myasthenia gravis and Lambert-Eaton syndrome. Neurology 1989;39:267A.

12 Vincent A, Newsom-Davis J. Acetylcholine receptor antibody as a diagnostic test for myasthenia gravis: results in 153 validated cases and 2967 diagnostic assays. J Neurol in 153 validated cases and 2967 diagnos

13 Wiles CM, Karni Y, Nicklin J. Laboratory testing of muscle function in the management of neuromuscular disease. function in the management of neuromuscular
$J$ Neurol Neurosurg Psychiatry 1990;53:384-7. 